\section{Scientific abstracts from the 7th International Barcode of Life Conference}

\author{
Nombolo Mdhluli Conference Centre, \\ Skukuza Rest Camp, Kruger National Park, \\ South Africa
}

\section{Résumés scientifiques du 7e Conférence internationale "Barcode of Life"}

\author{
Nombolo Mdhluli Conference Centre, \\ Skukuza Rest Camp, Kruger National Park, \\ South Africa
}

\section{Guest Editors}

Sarah J. Adamowicz

Centre for Biodiversity Genomics,

Biodiversity Institute of Ontario \&

Department of Integrative Biology,

University of Guelph

Guelph, Ontario, Canada

Peter M. Hollingsworth

Royal Botanic Garden Edinburgh

Edinburgh, United Kingdom

Sujeevan Ratnasingham

Centre for Biodiversity Genomics,

University of Guelph

Guelph, Ontario, Canada

Michelle van der Bank

African Centre for DNA Barcoding

Department of Botany and Plant Biotechnology,

University of Johannesburg

Johannesburg, South Africa

\section{Directrice scientifique invitées}

Sarah J. Adamowicz

Centre for Biodiversity Genomics,

Biodiversity Institute of Ontario \&

Department of Integrative Biology,

University of Guelph

Guelph (Ontario) Canada

Peter M. Hollingsworth

Royal Botanic Garden Edinburgh

Edinburgh, United Kingdom

Sujeevan Ratnasingham

Centre for Biodiversity Genomics,

University of Guelph

Guelph (Ontario) Canada

Michelle van der Bank

African Centre for DNA Barcoding

Department of Botany and Plant Biotechnology,

University of Johannesburg

Johannesburg, South Africa

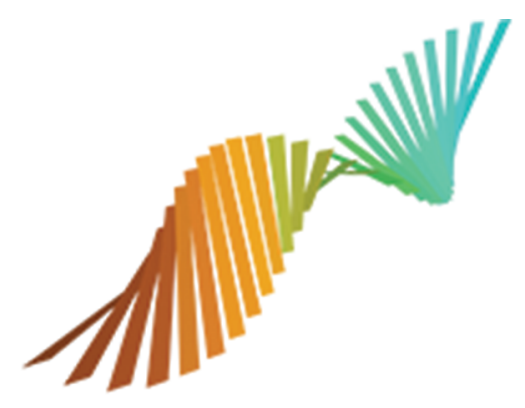

7 TH INTERNATIONAL

BARCODEOFLIFE

C ONFERENCE $\mid$ NOV 20-24 2017 